\title{
"PAZ DOMÉSTICA": \\ FIGURAÇÃO DO CASAMENTO EM RESSURREIÇÃO
}

\author{
Amanda Rios Herane \\ Universidade de São Paulo \\ São Paulo, Brasil
}

\begin{abstract}
Resumo: Este artigo consiste em uma abordagem de Ressurreição (1872), primeiro romance de Machado de Assis. Na obra, o comportamento do protagonista Félix é visto pelo narrador como fruto da natureza singular do personagem. Félix teria um caráter incongruente que o tornaria propenso a desconfiar, em razão do que sentiria ciúmes infundados de Lívia e teria dúvidas quanto a se casar com ela. O narrador parte da premissa de que o matrimônio seria um benefício inquestionável, de modo que somente um desconfiado como Félix o refutaria. No entanto, esse mesmo narrador entra em contradição ao expor que o casamento poderia ter aspectos problemáticos para alguns pares do romance. $\mathrm{O}$ texto que se segue buscará explorar essa contradição.
\end{abstract}

Palavras-chave: Ressurreição; narrador; casamento.

\section{"Domestic peace": marriage as featured in ressurreição}

\begin{abstract}
This article discusses Ressurreição (1872), the first novel by Machado de Assis. In the book, the narrator presents the behavior of the main character, Félix, as determined by his particular nature. According to the narrator, Félix possessed an incoherent personality, which would make him prone to suspicions, leading him to feel jealous, with no grounds at all, about his fiancée Livia and to question whether he should really marry her. The narrator works on the premise that marriage is an unquestionable benefit, which only a suspicious person like Félix would refuse. However, the narrator contradicts himself by recognizing that marriage could have problematic implications to some of the couples presented in the novel. The following analysis focuses on this contradiction.
\end{abstract}

Keywords: Ressurreição; narrator; marriage. 
Ressurreição (1872), primeiro romance de Machado de Assis, provocou estranhamento em meio à crítica desde sua publicação. É possível dizer que, de modo geral, os críticos do período oitocentista tentaram ajustar o livro a padrões literários vigentes no século XIX - tais como a necessidade de que a obra apresentasse um caráter mais nacional e/ou mais sentimental -, mas encontraram dificuldade nessa tarefa, do que resultou o incômodo expresso nos artigos sobre Ressurreição. ${ }^{1}$ No século XX, a crítica tendeu a separar a obra machadiana em dois momentos, por entender que as primeiras produções de Machado de Assis não traziam ainda um teor "realista" aguçado, como nos textos escritos pelo autor a partir de Memórias póstumas de Brás Cubas (1880). Essa divisão da obra machadiana revela um desconforto da crítica quanto às obras tidas como pertencentes à "primeira fase" de Machado de Assis, dentre as quais se inclui Ressurreição.

Contudo, o primeiro romance de Machado de Assis pode ser visto como dissonante não só em relação a determinados paradigmas literários ou ao conjunto da obra machadiana: há dissonâncias no interior da própria narrativa, na medida em que seu argumento apresenta inconsistências. Talvez a mais flagrante destas se encontre no discurso contraditório do narrador de Ressurreição acerca do casamento, ${ }^{2}$ capaz de nos fazer repensar a avaliação desse mesmo narrador sobre o comportamento de Félix, protagonista do romance.

Em Ressurreição, Félix, um médico que deixara de trabalhar após receber uma herança, desiste de se casar com a viúva Lívia, que chegara a se tornar sua noiva, devido às constantes suspeitas por ele engendradas. Aparecem na obra alguns obstáculos potenciais à união do casal: Meneses, advogado conhecido de Félix, enamora-se de Lívia; Raquel, cujos pais faziam parte das relações de Félix, é apaixonada pelo herói; e há ainda o vilão Luís Batista, que, embora fosse casado, cobiçava Lívia, motivo pelo

\footnotetext{
${ }^{1}$ A ideia de que Ressurreição não se enquadrava em expectativas literárias românticas baseia-se em: GUIMARÃES, Hélio de Seixas. Os leitores de Machado de Assis: o romance machadiano e o público de literatura no século 19. São Paulo: Nankin; Edusp, 2004.

${ }^{2}$ Pontuemos que a importância do tema do casamento em Ressurreição já foi indicada por Silviano Santiago na década de 1960. Conforme o autor, o núcleo gerador da estrutura da obra seria a relação amor/casamento. Cf. SANTIAGO, Silviano. Jano, Janeiro. TERESA - revista de literatura brasileira, $\mathrm{n}$. 6/7. São Paulo: Editora 34, 2006. p. 437.
} 
qual tenta separá-la de Félix, escrevendo para o protagonista uma carta em que difamava sua noiva.

Esses empecilhos quase "clássicos" (os rivais, a carta difamatória) não constituem, porém, impedimentos efetivos. Meneses e Raquel passam a apoiar Félix e Lívia quando descobrem que ambos estavam apaixonados, e a carta de Luís Batista, embora avive as desconfianças do herói, revela-se uma farsa. Sendo assim, o verdadeiro obstáculo para a realização do casamento de Félix com Lívia seria o próprio Félix, que, de acordo com o narrador de Ressurreição, seria inatamente propenso a desconfiar, razão pela qual sentiria ciúmes infundados da noiva e teria dúvidas quanto a se casar.

Para o narrador do romance, o caráter de Félix seria composto por aspectos contrários que não se compatibilizariam, o que tornaria o personagem pusilânime:

Do seu caráter e espírito melhor se conhecerá lendo estas páginas, e acompanhando o herói por entre as peripécias da singelíssima ação que empreendo narrar. Não se trata aqui de um caráter inteiriço, nem de um espírito lógico e igual a si mesmo; trata-se de um homem complexo, incoerente e caprichoso, em quem se reuniam opostos elementos, qualidades exclusivas e defeitos inconciliáveis.

Duas faces tinha o seu espírito, e conquanto formassem um só rosto, eram todavia diversas entre si, uma natural e espontânea, outra calculada e sistemática. Ambas porém se mesclavam de modo que era difícil discriminá-las e defini-las. Naquele homem feito de sinceridade e afetação tudo se confundia e baralhava. Um jornalista do tempo, seu amigo, costumava compará-lo ao escudo de Aquiles, - mescla de estanho e ouro, - "muito menos sólido", acrescentava ele. ${ }^{3}$

Seguindo-se o discurso do narrador, Félix, por ser fraco, não teria a solidez necessária para ser constante e confiante. Nesse quadro, as desconfianças do protagonista, às quais se atribui sua indecisão pelo casamento, seriam fruto de um caráter idiossincrático.

É possível pensarmos que tal ideia alia-se, na obra, ao pressuposto do narrador de que o casamento seria um benefício inquestionável, de sorte que apenas um excêntrico como Félix colocaria em causa a instituição. Diga-se, a propósito, que o narrador procura reafirmar seu pressuposto sobre o matrimônio ao atestar a felicidade

\footnotetext{
${ }^{3}$ ASSIS, Machado de. Ressurreição. Rio de Janeiro: Civilização Brasileira, 1977. p. 64.
} 
dos pares casados de Ressurreição. Contudo, ele acaba deixando transparecer a existência de insatisfações importantes na vida conjugal desses casais, o que nos permite questionar se a atitude de Félix frente ao casamento resultaria somente da natureza singular do personagem.

\section{Os casais de Ressurreição}

Em Ressurreição, além dos personagens Félix e Lívia, são-nos apresentados Viana, irmão de Lívia, Luís, o filho que Lívia tivera em seu primeiro casamento, e os seguintes pares: Raquel e Meneses, que se casam no desfecho da intriga; dona Matilde e o coronel Morais, pais de Raquel; Luís Batista e sua mulher, Clara; Cecília e Moreirinha - observando-se que alguns escravos aparecem na obra, mas não têm participação no desenvolvimento do enredo. Esses personagens eram conhecidos de Félix, de Lívia, ou de ambos, estando quase todos direta ou indiretamente vinculados ao caso amoroso do par central.

Viana, almejando uma aliança de família com Félix, incentivava o romance da irmã com o protagonista. A presença de Luís, oferecendo a Félix uma visão de Lívia no papel de mãe, contribuíra para que o herói, cuja intenção inicial era a de ter somente uma aventura com Lívia, decidisse construir um relacionamento mais sério com ela. Como já apontado, Raquel e Meneses chegaram a causar tensões entre Félix e Lívia, mas logo passaram a ajudá-los. O coronel Morais e dona Matilde deram a festa em que o casal principal se conheceu; Luís Batista fez-se o vilão da história ao escrever, às vésperas do casamento que não chegou a ser concretizado, a carta que reacendeu as dúvidas do herói. Cecília, por fim, não chega a ter relação com a história amorosa do par central, mas aparece na trama como amante de Félix antes de o personagem conhecer Lívia, ilustrando o modo como o protagonista costumava encarar seus relacionamentos - Moreirinha é o próximo amante de Cecília, após o rompimento dela com Félix.

De modo geral, portanto, as figuras de Ressurreição estão ligadas ao desenrolar do relacionamento entre Félix e Lívia, mas seu papel não se limita a isso. Notemos que a maioria dos personagens do romance divide-se em pares já casados (dona Matilde e o coronel Morais; Clara e Luís Batista) e casais que são formados no decorrer da trama 
(Félix e Lívia; Raquel e Meneses; Cecília e Moreirinha) - ressaltando-se que, dentre esses últimos, ao que tudo indica, apenas Raquel e Meneses chegaram a assumir uma união legal. Assim, pode-se dizer que os personagens de Ressurreição são em grande medida definidos por seus relacionamentos amorosos ou por suas vidas conjugais, funcionando como elementos que sustentam o discurso do narrador sobre o casamento.

Atenhamo-nos, primeiramente, ao casal dona Matilde / coronel Morais. Conforme a descrição do narrador:

\begin{abstract}
A mulher do coronel era o tipo da mãe de família. Tinha quarenta anos, e ainda conservava na fronte, embora secas, as rosas da mocidade. Era uma mistura de austeridade e meiguice, de extrema bondade e extrema rigidez. Gostava muito de conversar e rir, e tinha a particularidade de amar a discussão, exceto em dous pontos que para ela estavam a acima das controvérsias humanas: a religião e o marido. A sua melhor esperança, afirmava, seria morrer nos braços de ambos. Dizia-lhe Félix às vezes que não era acertado julgar pelas aparências, e que o coronel, excelente marido em reputação, fora na realidade pecador impenitente. Ria-se a boa senhora destes inúteis esforços para abalar a boa fama do esposo. Reinava uma santa paz naquele casal, que soubera substituir os fogos da paixão pela reciprocidade da confiança e da estima. ${ }^{4}$
\end{abstract}

Destaquemos da passagem que dona Matilde negava-se a estabelecer qualquer discussão sobre o coronel e não se deixava abalar nem mesmo pela insinuação de que o marido a traía. Essa atitude é traduzida como "confiança" pelo narrador, sendo a "confiança", somada à substituição da "paixão" pela "estima", o elemento responsável, sob o ponto de vista do mesmo narrador, pela vida conjugal pacífica de dona Matilde e do coronel.

O casamento de dona Matilde seria, assim, um exemplo de união bemsucedida; entretanto, a tal "paz" conquistada pela mulher do coronel dava-se ao custo de uma "confiança" que estava mais para uma "cegueira" - visto que dona Matilde evitava deparar-se com discussões que pusessem em risco sua crença na virtude do marido -, e também ao custo de um amortecimento dos sentidos, da substituição dos "fogos da paixão" pela brandura da "estima".

\footnotetext{
${ }^{4}$ Idem, p. 74.
} 
Se dona Matilde se esquivava de colocar em xeque a reputação do coronel, é porque desejava que o marido não a traísse, e queria crer que ele, de fato, não lhe fora infiel. A personagem também esperaria que seu casamento fosse movido pela paixão paixão essa que o coronel talvez buscasse fora de casa - dado que, segundo o narrador, dona Matilde soubera substituir a paixão pela estima. Sendo assim, era à força de fantasiar que o marido atendia às suas expectativas, ou de abafar essas mesmas expectativas - de lidar, em suma, com frustrações - que dona Matilde conseguira manter a "santa paz" de seu casamento.

Também Clara sustentava seu casamento mediante frustrações:

Mas a mulher dele [de Luís Batista]? A mulher dele, amigo leitor, era uma moça relativamente feliz. Estava mais que resignada, estava acostumada à indiferença do marido. Dera-lhe a Providência essa grande virtude de se afazer aos males da vida. Clara havia buscado a felicidade conjugal com a ânsia de um coração que tinha fome e sede de amor. Não logrou o que sonhara. Pedira um rei e deram-lhe um cepo. Aceitou o cepo e não pediu mais.

Todavia o cepo não o fora tanto antes do casamento. Paixão não a teve nunca pela noiva; teve, sim, um sentimento todo pessoal, mistura de sensualidade e fatuidade, espécie de entusiasmo passageiro, que os primeiros raios da lua de mel abrandaram até apagá-lo de todo. A natureza readquiriu os seus aspectos normais; a pobre Clarinha, que havia ideado um paraíso no casamento, viu desfazer-se em fumo a sua quimera, e aceitou passivamente a realidade que lhe deram, - sem esperanças, é certo, mas também sem remorsos.

Faltava-lhe, - e ainda bem que lhe faltava, - aquela curiosidade funesta com que o anfíbio clássico, desenganado do cepo, entrou a pedir um rei novo, e veio a ter uma serpente que o engoliu. ${ }^{5}$ A virtude salvou-a da queda e da vergonha. Lastimava-se, talvez, no refúgio do seu coração, mas não fez imprecações ao destino. E como nem tinha força de aborrecer, a paz doméstica nunca fora alterada; ambos podiam dizer-se criaturas felizes. ${ }^{6}$

Antes de explorar a passagem, ressaltemos que Luís Batista desejava Lívia e não seria incomum que tivesse amantes, como indica o diálogo a seguir:

\footnotetext{
${ }^{5}$ Referência à fábula "Les Grenouilles qui demandent un roi" ("As rãs que pedem um rei"), de Esopo, retomada por La Fontaine. ESOPO. Le Grenouilles qui demandent un roi. In: Société d'Édition "Le Belles Lettres", 1927. p. 32. Fables. Paris:

${ }^{6}$ ASSIS, Machado de. Ressurreição, cit., p. 107-108.
} 
- [fala de Baptista a Félix] Assisto portanto ao seu penúltimo almoço de rapaz solteiro. Há muita gente que ainda não acredita. Creio que o senhor tinha fama de celibatário convencido, e pela regra, um celibatário convencido é um noivo à mão. Também eu era assim; e contudo... O casamento é bom; tem seus inconvenientes, como tudo neste mundo; mas é bom, com a condição única de o aceitarmos como ele deve ser...

- Um pouco livre? disse Félix sorrindo.

- Não sei se pouco ou muito, é questão de temperamento. O essencial é que seja livre. Eu assim o entendo e pratico; sou um pecador miserável, confesso, mas tenho ao menos o mérito de não ser hipócrita, e agora mesmo... ${ }^{7}$

As traições do marido não deviam ser desconhecidas de Clara, até porque Luís Batista não parecia fazer questão de escondê-las, como revela a naturalidade com que as expõe a Félix. Nesse quadro, a "indiferença" que Clara via no marido - e que frustrava a ânsia da personagem por amor - poderia corresponder ao fato de que Luís Batista não se dispunha nem mesmo a fingir fidelidade, não permitindo que Clara pudesse se iludir quanto a ele - "solução" de dona Matilde em relação ao coronel -, restando à moça, como caminho para conservar seu casamento, a resignação.

É possível inscrever o problema da traição masculina, colocado nos exemplos de Clara e de dona Matilde, no contexto matrimonial do Brasil oitocentista. De acordo com Mary Del Priore, no Brasil do século XIX, "a fidelidade do marido não era apenas considerada utópica, segundo os viajantes, ${ }^{8}$ mas até ridicularizada". ${ }^{9}$ Ainda segundo a autora: "A fidelidade conjugal era sempre tarefa feminina; a falta de fidelidade masculina vista como um mal que se havia de suportar. É sobre a honra e a fidelidade da esposa que repousava a perenidade do casal". ${ }^{10}$ Essa perenidade devia ser, aliás, algo em que as mulheres seriam impelidas a se ancorar, pois, conforme Priore, não havia mercado livre aberto à mão de obra feminina, o que - depreende-se - dificultaria o sustento de uma mulher que decidisse se separar do marido. Além disso, mulheres separadas eram tidas por maus exemplos, devendo-se evitar o contato com elas.

\footnotetext{
${ }^{7}$ Idem, p. 159.

${ }^{8}$ A autora se refere a relatos de cronistas estrangeiros sobre o Brasil do século XIX.

${ }^{9}$ PRIORE, Mary Del. História do amor no Brasil. São Paulo: Contexto, 2006. p. 181.

${ }^{10}$ Idem, p. 187.
} 
Os casamentos do coronel Morais e de Luís Batista tematizam a infidelidade masculina, que não seria exceção no Brasil do século XIX. O temor do adultério feminino aparece também em Ressurreição, como se vê em relação a Clara, a quem, digamos que por "sorte", faltava, segundo o narrador, a "curiosidade funesta" que poderia levá-la a procurar um outro homem - um "rei novo" -, ainda que seu marido fosse um "cepo". Essa falta de curiosidade teria, para esse mesmo narrador, salvado Clara "da queda e da vergonha", comentário que indica a condenação social a que estavam submetidas as mulheres adúlteras.

O narrador reconhece, portanto, que não faltariam a Clara motivos para trair Luís Batista - embora talvez fossem mais fortes os motivos para não traí-lo - e admite explicitamente que era apenas se resignando, ou, pior, até se acostumando à "indiferença do marido", que a personagem teria condições de suportar seu casamento. Mesmo assim, o narrador afirma que Clara era feliz, visto que sua passividade a impedia de abalar a "paz doméstica". Por outro lado, ainda que seja para elogiar o comportamento de Clara, ele acaba postulando a insatisfação da personagem, e com isso deixa transparecer o incômodo provocado pela disparidade na relação entre os gêneros no Brasil do século XIX.

Embora o narrador não chegue a enunciar isto, também o casamento de dona Matilde não era satisfatório, envolvendo a traição de seu marido - ainda que, nesse caso, não comprovada - e a falta de paixão, assim como no matrimônio de Clara faltava amor. Dona Matilde, contudo, recusava-se a considerar a infidelidade do coronel e compensava a ausência de paixão com estima, numa atitude "conformada" - como a de Clara - que é apoiada pelo narrador, na medida em que teria permitido à personagem manter a paz de seu casamento, com o que ela teria conquistado a felicidade.

Diga-se, a propósito, que Lívia lastimava ter perturbado a "paz doméstica" em seu primeiro casamento, o que teria ocorrido devido à sua tentativa de fazer com que o marido a amasse como ela esperava:

Era um homem apático e frio; honesto, é verdade, e bom coração, mas falávamos língua diversa e não nos podíamos entender. Confiei todavia na influência do amor. Empreendi a tarefa de o trazer à atmosfera dos meus sentimentos, errada tentativa, que só me produziu atribulação e cansaço. Fatigava-o com isso a que ele chamava 
pieguices poéticas; da fadiga passou à exasperação, da exasperação ao tédio. No dia em que o tédio apareceu conheci que o mal estava consumado. Quis emendá-lo e não pude. Tinha feito da nossa vida conjugal um deserto; e se a minha alma clamava contra o destino, minha consciência me acusava de um erro, o erro de haver perturbado a paz doméstica, a troco de um sonho que não veio. Não me faço melhor do que sou, bem vês; mas uma parte da culpa não será da natureza que me fez tão pueril? ${ }^{11}$

Ressaltemos que o ideal de um casamento pautado pelo amor era compartilhado por Lívia, Clara e dona Matilde, não tendo nenhuma das três conseguido atender a essa expectativa. Tendo-se em vista os exemplos de Clara e de dona Matilde, o lamento de Lívia reforçaria o argumento do narrador de que a "paz doméstica", mesmo se dando ao custo de frustrações, conduziria à felicidade.

É importante ponderarmos que a frustração com o matrimônio não seria um problema exclusivo das mulheres, se entendermos que a traição masculina, tida quase como uma regra social, poderia corresponder a uma manifestação da insatisfação também dos homens quanto à instituição do casamento. Talvez devido a essa percepção é que Félix se incomodasse com a infidelidade do coronel Morais - por vezes "tocando na ferida" de dona Matilde - e com as traições de Luís Batista, conforme revela o pensamento do herói:

Um sobrinho do coronel indicou-lhe a mulher do Batista; era uma moça de vinte anos, loura, assaz bonita e digna de inspirar amores. Porque motivo, o marido, casado há pouco, queria ir queimar a um templo estranho os perfumes que a esposa merecia? ${ }^{12}$

Considerando-se que, de modo geral, os casamentos no Brasil do século XIX não partiam da escolha dos cônjuges, mas eram determinados por grupos familiares, ${ }^{13} \mathrm{e}$ que essa realidade matrimonial brasileira entrava em contradição com um ideal de união por amor (que aparecia na literatura do período e constituía um princípio do casamento

\footnotetext{
${ }^{11}$ ASSIS, Machado de. Ressurreição, cit., p. 119-120.

${ }^{12}$ Idem, p. 78.

${ }^{13}$ Cf. D'INCAO, Maria Ângela. Mulher e família burguesa. In: PRIORE, Mary Del (Org.). História das mulheres no Brasil. São Paulo: Contexto, 2009. p. 223-240; SAMARA, Eni de Mesquita. Estratégias matrimoniais no Brasil do século XIX. Revista Brasileira de História, v.8, n.15, São Paulo, set. 1987/fev. 1988. p. 91-105.
} 
burguês), é de se esperar que tais matrimônios gerassem frustrações, tanto para homens quanto para mulheres - ainda que os homens, nessa sociedade machista, tivessem certas prerrogativas sobre a esposa, dentre as quais se inclui a de estarem socialmente "habilitados" a trair, diferentemente do que ocorria a suas mulheres.

A insatisfação decorrente de um casamento baseado em arranjos entre famílias, característico da organização familiar patriarcal, é enfatizada por Antonio Candido. Segundo o autor, dentro da estrutura patriarcal:

As relações entre homens e mulheres eram diretamente ligadas ao tipo de casamento - considerado um ato importante demais para ser deixado à vontade das partes interessadas. [...] Isso, evidentemente, é uma concepção de acordo com a qual o indivíduo está inteiramente subordinado aos interesses do grupo e obrigado a adaptar sua conduta aos valores mantidos por esse grupo. ${ }^{14}$

Candido centra-se no impacto que essa forma de união teve sobre os que ficavam na periferia do núcleo familiar patriarcal, legalizado, composto pelo casal branco e seus filhos legítimos. Para o autor, as "irregularidades sexuais dos homens" (ou seja, as relações que fugiam do casamento legal), facilitadas, como se depreende das ideias de Candido, pelas condições em que viviam escravas e agregadas, eram "quase impostas por um tipo de casamento que, quase sempre assumindo a forma mais rígida do contrato, excluía a ideia de satisfações emocionais". ${ }^{15}$

Ao que indicam obras que abordam o matrimônio no Brasil oitocentista, ${ }^{16}$ mesmo nos meios urbanos, nos quais a burguesia estava em ascensão, os casamentos baseavam-se em interesses de grupos familiares. Assim, o problema da insatisfação decorrente de matrimônios arranjados não seria alheio a figuras como as que

\footnotetext{
${ }^{14}$ Tradução minha para: "The relations between men and women were directly related to the type of marriage - considered as an act that was too important to be left to the volition of the interested parties. [...] This, as is evident, is a concept according to which the individual is entirely subordinated to the interests of the group and obliged to adapt his conduct to the values which it maintains". CANDIDO, Antonio. The Brazilian family. In: SMITH, T. Lynn; MARCHANT, Alexander (Ed.). Brazil: portrait of half a continent. New York: The Dryden Press, 1951. p. 297.

${ }^{15}$ Tradução minha para: "almost imposed by a type of marriage which, nearly always assuming the most rigid form of the contract, excluded the very idea of emotional satisfactions". Idem, p. 303.

${ }^{16}$ Ver nota 13.
} 
encontramos em Ressurreição, que pertenciam às classes mais abastadas da cidade do Rio Janeiro do período.

Acrescente-se, ainda, que o distanciamento físico a que homens e mulheres estavam submetidos no interior do casamento podia também ser uma fonte de insatisfação para os casais. Conforme Mary Del Priore, havia no século XIX um culto à pureza das mulheres, que reforçava a distância entre os cônjuges e tinha por resultado, nos termos da autora, que "as mulheres se tornavam beatas ou pudicas azedas, cumpridoras de seus deveres, e os homens, bastiões de um respeitoso egoísmo, abstendo-se de toda e qualquer demonstração em relação às suas esposas". ${ }^{17}$ Para Priore, esse distanciamento era acentuado pela tradição religiosa, que promovia uma divisão de papéis, considerando que "o marido tinha necessidades sexuais e a mulher se submetia ao papel de reprodutora". ${ }^{18}$

A constituição dos casamentos no Brasil do século XIX envolvia, assim, interesses, insatisfações emocionais, afastamento dos corpos, infidelidade. Não deixemos de ponderar que a manutenção do casamento, correspondendo a uma expectativa social, possivelmente também era, em certa medida, recompensadora. Contudo, os exemplos de Clara e de dona Matilde, insatisfeitas com casamentos que não correspondiam às suas expectativas de encontrar amor ou paixão e que lhes traziam o ônus das traições dos maridos, deixam emergir o caráter problemático que os matrimônios do período podiam ter.

Desse modo, os dois exemplos abalam, por um lado, a premissa do narrador de que o matrimônio seria um benefício inquestionável. Por outro, dão apoio à perspectiva conservadora desse mesmo narrador que, a partir dos casos de Clara e de dona Matilde, encaminha seu discurso no sentido de afirmar que, se não questionado, o casamento dá certo. Ou, em outros termos: para o narrador de Ressurreição, se a mulheres souberem ficar cegas ou resignadas frente a questões como a da infidelidade - podendo os homens ficar um pouco ou bastante livres, nos termos de Luís Batista, para buscarem a satisfação fora de casa -, é possível manter a "paz doméstica", tida pelo narrador como condição para a felicidade. Cabe sublinhar, a propósito, que essa felicidade, ou êxito do

\footnotetext{
${ }^{17}$ PRIORE, Mary del. História do amor no Brasil, cit., p. 178-179.

${ }^{18}$ Idem, p. 179.
} 
matrimônio, não corresponde ao cumprimento das expectativas dos envolvidos, mas à manutenção não conflituosa da própria instituição e à continuidade da vida cotidiana segundo os valores vigentes.

Assim como as vidas conjugais de dona Matilde com o coronel Morais e de Clara com Luís Batista, os relacionamentos dos outros pares de Ressurreição também podem ilustrar certas concepções do narrador. Pensemos, inicialmente, em Cecília e Moreirinha. Sugere-se no romance que Cecília está ligada ao universo da prostituição, tal como se depreende desta passagem, relativa ao rompimento da personagem com Félix:

Meia hora depois despedia-se Félix de Cecília declarando-lhe que saía dali como um gentleman, e que ela receberia os meios necessários para viver até que o esquecesse de todo.

Cecília recusou esse ato de generosidade. Espantou-o imensamente tamanho desinteresse; concluiu que ela teria algum amor em perspectiva. $^{19}$

De acordo com Félix, portanto, Cecília sustentava-se dos relacionamentos que estabelecia. A personagem, como insinua o narrador, também seria promíscua, equivalendo essa promiscuidade - ainda conforme a fala do narrador - aos "recursos" formas de sustento? - de uma mulher nas condições de Cecília (condições essas que o narrador não chega a explicitar quais seriam):

- [fala de Cecília a Meneses] Posso jurar-lhe que durante todo este tempo pertenci-lhe [a Félix] exclusivamente.

O juramento de Cecília não devia valer muito aos olhos de um homem que conhecesse bem todos os recursos de uma mulher naquelas condições. Mas o nosso Meneses era ingênuo em cousas tais. Saiu de lá cheio de piedade. ${ }^{20}$

Após o fim do relacionamento com Félix, Cecília tornara-se amante de Moreirinha. Moreirinha, a princípio, colocava à relação com Cecília a ressalva de que lhe trazia gastos, mas acreditava que esses gastos valiam a pena, na medida em que a

\footnotetext{
${ }^{19}$ ASSIS, Machado de. Ressurreição, cit., p. 70.

${ }^{20}$ Idem, p. 73.
} 
moça apresentava qualidades. Com o tempo, porém, Cecília arranca as finanças do amante e passa a persegui-lo de tal modo que ele chega a pedir refúgio na casa de Félix. A "mudança no caráter" de Cecília chama a atenção do protagonista, mas ele logo lhe arranja uma explicação: "Compreendeu facilmente que era obra do próprio amante. A rola fizera-se gavião, pela única razão de que Moreirinha lhe dera ensejo de conhecer a própria força". ${ }^{21}$

O envolvimento com Cecília, que inicialmente pareceu auspicioso, revelou-se, assim, destrutivo para Moreirinha, que passou a viver em uma "miserável posição" nas palavras do narrador -, devido às demandas da amante, as quais o narrador julgava infindáveis:

\footnotetext{
Não era preciso grande perspicácia para compreender que aquilo tudo era obra de Cecília. Nem ficaria longe de verossimilhança quem afiançasse que Moreirinha estava eternamente condenado ao capricho daquela mulher. Não tinha de certo o rapaz com que lhe satisfazer todas as vaidades e necessidades; ela incumbia-se de abrir outras verbas no orçamento da receita, mediante um bem combinado sistema de impostos. ${ }^{22}$
}

O relacionamento de Cecília e Moreirinha, que dá espaço a esse desregramento da moça - ao seu incessante "capricho" - e também ao de Moreirinha - que atende os caprichos de Cecília e se consome -, pode ser entendido como uma lição sobre os perigos do mundo da rua. Isso porque é se envolvendo com uma mulher associada ao universo da prostituição - vinculado a esse mundo da rua - que Moreirinha se "põe a perder".

Nesse quadro, a relação de Moreirinha e Cecília seria um exemplo conveniente ao discurso moralista do narrador, se entendido como prova do risco de relacionamentos que fogem da conformidade do lar - caso os homens não saibam dar limites a eles, pois Félix colocara Cecília em seu "devido lugar", não lhe dando espaço para "abusos". Também o relacionamento de Raquel e Meneses pode ser pensado em relação ao

\footnotetext{
${ }^{21}$ Idem, p. 133.

${ }^{22}$ Idem, p. 134.
} 
discurso do narrador, na medida em que oferece um contraponto ao de Lívia e Félix, atestando a felicidade que o casamento proporcionaria.

A ideia de que o casamento traria a felicidade é posta no capítulo final de Ressurreição, "Hoje", em que o narrador apresenta a situação dos pares Raquel / Meneses, dona Matilde / coronel Morais e de Lívia e Félix, passados dez anos da história que narra. Pontuemos que os outros dois pares do romance não aparecem no desfecho, até porque Cecília e Moreirinha não eram casados, e o casal Clara / Luís Batista envolve o vilão da trama. Nas palavras do narrador:

Dez anos volveram sobre os acontecimentos deste livro, longos e enfastiados para uns, ligeiros e felizes para outros, que é a lei uniforme desta mofina sociedade humana.

Ligeiros e felizes foram eles para Raquel e Meneses, que eu tenho a honra de apresentar ao leitor, casados, e amantes ainda hoje. A piedade os uniu; a união os fez amados e venturosos. ${ }^{23}$

Eis a situação desse casal. Quanto a dona Matilde e o coronel, já haviam falecido, mas ainda assim o narrador invoca a felicidade que alcançaram em vida, e que os teria acompanhado mesmo depois de mortos: "O coronel e dona Matilde, com poucos meses de intervalo, foram continuar na eternidade a doce união que os distinguira neste mundo". ${ }^{24}$

Félix, mesmo não tendo mais vínculo com Lívia, continuava desconfiado da moça e ficara infeliz. O estado de Lívia é visto como intermediário entre a felicidade dos casais abordados e a infelicidade do herói. Lívia havia se concentrado em elaborar a história que tivera com Félix, tarefa que lhe rendia frutos, pois, segundo o narrador: "à proporção que volvem os anos, [Lívia] espiritualiza e santifica a memória do passado. Os erros de Félix estão esquecidos; o traço luminoso, ${ }^{25}$ de que lhe falara na última entrevista, foi só o que lhe ficou". ${ }^{26}$ De acordo com o narrador, para superar esse

\footnotetext{
${ }^{23}$ Idem, p. 178.

${ }^{24}$ Idem, p. 179.

${ }^{25}$ Referência a esta fala de Lívia: "Acredite o que lhe digo; amemo-nos de longe; sejamos um para o outro como um traço luminoso do passado, que atravesse indelével o tempo, e nos doure e aqueça os nevoeiros da velhice." (Idem, p. 177.)

${ }^{26}$ Idem, p. 179.
} 
passado, Lívia recolhera-se o quanto pôde da sociedade, evitando aparições públicas e compensando o pouco contato social com o esforço em educar o filho, que se tornara o "consolo e companhia de sua velhice". ${ }^{27}$

Contrastando o destino pouco feliz de Lívia e o destino infeliz do protagonista com os destinos felizes dos que se casaram - Raquel e Meneses - e dos que souberam preservar seu casamento, garantindo a "paz doméstica" - dona Matilde e o coronel -, o capítulo que fecha Ressurreição reforça a ideia de que o matrimônio deve ser assumido e mantido, que o narrador se esmera em sustentar no decurso da narrativa. A perspectiva de que a indecisão de Félix quanto ao casamento explica-se no quadro psicológico singular do personagem está afinada com essa visão, pois deixa intacta a instituição que o narrador não quer problematizar, na medida em que a relação conflituosa do herói com o matrimônio é percebida, nesse quadro, nos limites do âmbito individual. ${ }^{28}$ Ao mesmo tempo, e contraditoriamente, o narrador reconhece que a manutenção do casamento poderia se dar ao custo de frustrações - de modo que o matrimônio não seria uma questão problemática apenas para Félix -, mas sugere que se resignar com isso seria o caminho para uma união bem-sucedida.

Podemos entender as inconsistências a respeito do casamento, no discurso do narrador, como manifestação de uma visão ambígua desse mesmo narrador sobre a sociedade. No último parágrafo de Ressurreição, o narrador expõe a existência de uma tensão entre expectativas sociais - como a assunção do matrimônio, à qual Félix se recusa - e expectativas individuais: "Dispondo de todos os meios que o podiam fazer venturoso, segundo a sociedade, Félix é essencialmente infeliz. [...] Não se contentando com a felicidade exterior que o rodeia, quer haver essa outra das afeições íntimas, duráveis e consoladoras". ${ }^{29}$ Observamos aqui que, para o narrador do romance,

\footnotetext{
${ }^{27}$ Idem, p. 179.

${ }^{28}$ O caráter conservador de Ressurreição já foi apontado por Roberto Schwarz. Para o autor, nessa obra machadiana, bem como nos três romances subsequentes de Machado de Assis, haveria "a afirmação enfática da conformidade social, moral e familiar, que orienta a reflexão sobre os destinos individuais". SCHWARZ, Roberto. Ao vencedor as batatas: forma literária e processo social nos inícios do romance brasileiro. São Paulo: Editora 34; Duas cidades, 2000. p. 88. Também Silviano Santiago indicou a presença de um conservadorismo em Ressurreição, ainda que em outros termos. De acordo com o crítico, a estrutura do primeiro romance machadiano teria como núcleo gerador a relação amor / casamento como já mencionado -, sendo ambos os termos tratados de forma conservadora em Machado de Assis. Cf. SANTIAGO, Silviano. Jano, janeiro, cit.
}

${ }^{29}$ ASSIS, Machado de. Ressurreição, cit., p. 180. 
desejando uma felicidade - digamos - "essencial", Félix ficara "essencialmente infeliz", ao passo que, se se contentasse com uma "felicidade exterior", teria alcançado alguma felicidade. Nesse sentido, o narrador admite que o atendimento das expectativas sociais poderia não conduzir à felicidade das "afeições íntimas", mas seria a única alternativa para se obter alguma felicidade. É possível imaginarmos que essa perspectiva talvez refletisse os impasses da vida social carioca figurada em Ressurreição por Machado de Assis, não sem uma certa dose de perplexidade da parte do autor.

Referências:

ASSIS, Machado de. Ressurreição. Rio de Janeiro: Civilização Brasileira, 1977.

CANDIDO, Antonio. The Brazilian family. In: SMITH, T. Lynn; MARCHANT, Alexander (Ed.). Brazil: portrait of half a continent. New York: The Dryden Press, 1951.

D'INCAO, Maria Ângela. Mulher e família burguesa. In: PRIORE, Mary Del (Org.). História das mulheres no Brasil. São Paulo: Contexto, 2009.

ESOPO. Le Grenouilles qui demandent un roi. In: Fables. Paris: Société d'Édition "Le Belles Lettres", 1927.

GUIMARÃES, Hélio de Seixas. Os leitores de Machado de Assis: o romance machadiano e o público de literatura no século 19. São Paulo: Nankin; Edusp, 2004.

PRIORE, Mary Del. História do amor no Brasil. São Paulo: Contexto, 2006.

SAMARA, Eni de Mesquita. Estratégias matrimoniais no Brasil do século XIX. Revista Brasileira de História, v.8, n.15, São Paulo, set. 1987/fev. 1988.

SANTIAGO, Silviano. Jano, Janeiro. TERESA - revista de literatura brasileira, n. 6/7. São Paulo: Editora 34, 2006.

SCHWARZ, Roberto. Ao vencedor as batatas: forma literária e processo social nos inícios do romance brasileiro. São Paulo: Editora 34; Duas cidades, 2000.

Amanda Rios Herane é mestre em Literatura Brasileira pela Universidade de São Paulo, onde defendeu, no início de 2011, a dissertação Memória das ilusões: um estudo de 
Ressurreição, primeiro romance de Machado de Assis, sob a orientação do Prof. Dr. Hélio de Seixas Guimarães e com o auxílio da CAPES e da FAPESP. De seu trabalho com o primeiro romance machadiano também resultou o artigo "Ciúme e soterramento em Ressurreição", publicado em 2008 no periódico eletrônico Working Papers (University of Pennsylvania - Department of Romance Languages). E-mail: <herane@uol.com.br>

Recebido: 08/09/2011

Aprovado: 28/11/2011 